\title{
NOTAS DE BIBLIOGRAFIA E DE CRITICA
}

\author{
TH. HENRIQUE MAURER JR. - GRAMATICA DO LATIM VULGAR
}

- Livraria Acadêmica, Rio, 1959, $288 p p$.

Mais uma obra de inestimável valia passou a integrar a coleção "Biblioteca Brasileira de Filologia". Trata-se da GRAMATICA DO LATIM VULGAR, do Prof. Theodoro Henrique Maurer Jr., Catedrático de Filologia Românica da Universidade de São Paulo, nome largamente conhecido e prestigiado nos meios cientificos do Pais.

Esta sua contribuição ao estudo do Latim Vulgar vem preencher uma lacuna da bibliografia brasileira sôbre o assunto e surge ao encontro da necessidade premente de se produzirem no Brasil obras especializadas para o manuseio dos nossos alunos do curso de Letras. Os tratados em lingua estrangeira estāo hoje a preços proibitivos e de difícil aquisição.

Bem podemos aquilatar a soma de dificuldades que o autor encontrou pela frente, a fim de nos proporcionar tão exata e metódica sintese do pensamento dos grandes romanistas, acêrca de assuntos ainda hoje bastante controvertidos, buscando dirimir dúvidas e adotando pontos de vista próprios.

Dentro desta matéria, é obra inteiramente nova no Brasil e constitui clarissimo testemunho do grande surto que vêm alcançando os estudos lingüísticos no pais, sobretudo após a fundação das Faculdades de Filosofia. Já ultrapassamos a fase do pioneirismo e estamos empenhados a fundo em alargar a trilha aberta por grandes mestres brasileiros, entre os quais deve ser contado o Prof. Theodoro Henrique Maurer Jr., com muitos e indiscutiveis méritos.

As linhas gerais da obra estāo delineadas no prefácio. Em que pese a escassa bibliografia especializada, o autor propōe-se estudar 0 Latim Vulgar nos seus vários aspectos de lingua viva: fonética, morfologia, sintaxe e léxico. E alcançou plenamente o seu objetivo.

De inicio demonstra a necessidade de se conhecer melhor 0 Latim Vulgar - ou Latim Corrente - a língua do povo latino, da qual se originaram as línguas Românicas, malgrado a exigüidade de elementos para realizar a reconstrução daquela modalidade do Latim estritamente oral.

Lançou-se $\circ$ autor à difícil emprêsa e brindou-nos com magnífico repositório do que de melhor já se fêz no assunto, tudo analisando e confrontando, à luz da moderna lingüística. 
Para chegar a esta reconstituição, aplicou o único método viável em semelhante pesquisa: o histórico-comparativo.

Partindo da concordância entre as Línguas Românicas, indutivamente, alcança o estágio anterior dessas línguas e obtém a confirmação dos resultados obtidos por meio dos textos de escritores, das informações dos gramáticos latinos e através da epigrafia latina.

Seguiu o caminho natural do pesquisador, de acôrdo com a diretiva do sábio mestre Meillet:

"C'est donc par la grammaire comparée des langues romanes que se définit le latin vulgaire; c'est seulement en observant les résultats auxquels ont abouti les tendances que l'on en peut constater à coup sur l'existence. La grammaire comparée des langues romanes permet ainsi de reconnaitre, dans les particularités qu'offrent les textes vulgaires, celles qui indiquent les procès intéressants pour le linguiste".

De fato, os textos vulgares desempenham na pesquisa lingüística mera função confirmativa dos fatos. Na expressão de Salvatore Battaglia, nenhuma obra escrita é pròpriamente vulgar, nenhuma composição constitui pleno testemunho dessa latinidade vulgar; tôda obra escrita, por modesta e elementar, é sempre fruto da cultura, da escola, da trađição livresca. Nem as inscriçōes, de caráter mais popular, podem ser apresentadas como documentos genuinos do latim vulgar. O que há, na verdade, são obras que conservam "vulgarismos": palavras, sentidos particulares, modalidades gramaticais e sintáticas, isto é, fragmentos de uma realidade que o lingüista entrevê, mas que não pode contemplar em tôda a extensão e variedade.

Se no campo da lingüística indo-européia o método comparativo esbarra com uma hipótese insolúvel, torna-se, pela vez primeira, realidade científica na lingüística românica.

Dentro dêsse método, o autor deu ao Romeno o lugar proeminente que ocupa no conjunto das línguas românicas, para efeito da reconstituição do latim vulgar. Devido às circunstâncias históricas, o Romeno sofreu um isolamento prematuro e em conseqüência, poderia ter-se desgarrado da família românica.

Nestas condições, as formas encontradas nessa língua, mesmo que se verifiquem em uma ou outra língua românica apenas, têm valor probatório decisivo na configuração de sua origem latina.

Além do léxico, pela comparação das línguas românicas, seríamos capazes de reconstruir também a fonética e a morfologia do latim pré-romance. Na sintaxe, porém, semelhante reconstrução é naturalmente mais difícil. Como estabelecer a antiguidade de um fenômeno sintático?

No que toca ao conceito dêsse Latim Vulgar, o autor afasta-se da opinião mais geral, isto é, de que era a língua usada correntemente 
pela massa do povo latino, sem distinção de classes, como um todo complexo, segundo acentua Lot, em "Archivum Latinitatis":

"Le latin vulgaire n'est pas nécessairement la langue du vulgaire... C'est le latin en usage dans toutes les classes de la société, en haut comme en bas de l'échelle, c'est le latin tout court".

Endossa a opinião do saudoso Serafim da Silva Neto, o qual tem no Latim Vulgar a modalidade própria das baixas camadas, dos escravos, ao lado do latim familiar, das girias e do latim provincial.

Contudo, como o autor apenas expõe seu ponto de vista, sem discuti-lo e promete fazê-lo em próximo trabalho, não insistiremos tampouco no assunto.

Referindo-se à divisão da România em Ocidental e Oriental, o autor considera a Itália tôda incluída na primeira. Parece-nos que assim nāo está de acôrdo com a realidade lingüística, defendida por vários autores, entre êles $\mathrm{W}$. von Wartburg, que propōem a linha Spezzia-Rimini como a divisória entre as duas partes da România.

Os nacionais do pais "Romênia" devem ser "romenos" e não "rumenos"; êles falam o "romeno" e não o "rumeno". A grafia proposta pela Reforma Ortográfica, achamos, deve ser observada em vista da uniformizaçāo necessária da terminologia.

$\mathrm{Na} 1 .^{\mathrm{a}}$ parte da obra, apresenta o autor a Fonética do Latim Vulgar.

No que respeita à "quantidade", não encontramos nenhum conceito nôvo. Quanto ao "timbre", apóia a opiniāo de P. Fouché: na língua antiga, tanto as longas como as breves eram fechadas, um pouco menos estas últimas. A mínima diferença que deve ter existido no início ter-se-ia acentuado com o correr do tempo; daí, a maior abertura das breves.

A seguir, a evoluçāo das vogais tônicas e átonas, estas em posição inicial, medial (protônica e postônica), em silaba final, os ditongos $\mathrm{e}$ as anormalidades verificadas.

Com muito acêrto aborda a questão da pronúncia do "u" grego: " $u$ " na lingua popular e "ü" (escrito " $y$ ") na lingua culta, de tradição escolar. Nos helenismos que entraram por via oral, o "ü" passou naturalmente para o fonema mais fechado " $i$ ".

No capitulo do Consonantismo, explica como deve ter-se processado a palatalização das velares "c" e "g", e qual o tratamento dado às lábio-velares "qu" e "gu", à labiaI "b", à lateral "l", às semivogais "i" (y) e "u" (w), ao " $h$ " aspirado e a daptação que sofreram de modo geral os fonemas gregos, introduzidos artificialmente por via culta na lingua clássica.

Mereceram consideração especial as consonantes finais: o " $\mathrm{s}$ ", as geminadas, os grupos consonânticos simples e os complexos. 
No capitulo III, estuda a natureza do Acento no Latim Vulgar. Com sobejas razōes, admite o uso do acento intensivo já no Latim Clássico, concomitante ao de altura. $E$ como tôdas as línguas românicas possuem o acento intensivo, näo há dúvida que o Latim Vulgar também lhe dava maior ênfase.

Nesta questāo, o autor filia-se à corrente eclética moderna: nāo pode existir o acento intensivo sem o musical. Os gramáticos modernos pensam assim. Grammont escreve:

"Seja lá em que lingua fôr, cada fonema é dito em uma certa altura e é excepcional que os fonemas sucessivos de uma frase estejam na mesma nota; continuamente a voz se eleva ou se abaixa".

Isto aplica-se a tôdas as línguas, havendo variações apenas na gradação. As dúvidas que ainda persistem devem-se à escassez de documentos gramaticais. Os que existem são do século IV para cá, distantes, portanto, do período clássico.

Na 2.a parte, entra o autor em considerações mais amplas e profundas sôbre a Morfologia do Latim Vulgar.

Sem dúvida, é a mais importante. Uma língua pode afastar-se dos modelos primitivos na fonética e no léxico, até mesmo na sintaxe, sem perder a sua essência original e a sua estrutura. Continua sendo a mesma língua. Se, porém, a sua estrutura sofre abalos e se altera em um ou mais aspectos, é sinal de que a sua unidade deixou de xeistir. Produziu-se um fracionamento que a atingiu na essência: é outra lingua.

Essa modificação do sistema da língua sobrevém, em parte, como uma decorrência das alteraçōes fonéticas e léxicas. Eessas alterações repercutem também na sintaxe.

Assim, a perda das desinências casuais, a redução e o posterior desaparecimento das declinações, o desaparecimento do gênero neutro, a mudança de gênero dos substantivos, a diminuição do número das conjugaçóes, o desuso de certas formas verbais, ao lado da criação de outras novas e sem substituição às abandonadas, tiveram como ponto de partida a evolução dos sons, independente da ação psicológica, sempre atuante em uma língua viva.

Todos êsses pontos são magistralmente tratados.

A Sintaxe do Latim Vulgar vem considerada sob três aspectos:

a) as funçōes das categorias da gramática do latim vulgar;

b) a construção da frase;

c) a construçāo do período.

Uma nota explicativa justifica essa subdivisão. Lamenta-se o autor de não poder ir além das generalidades, pois a sintaxe sempre foi tratada superficialmente, tanto nas gramáticas expositivas como nas históricas. Acresce ainda a falta de bibliografia especializada. 
Examina, em primeiro lugar, o emprêgo das categorias gramaticais, pois o seu conhecimento é fundamental para a compreensāo da estrutura da frase e serve-lhe de introdução.

Em seguida, caracteriza a frase latina vulgar, em oposição à do latim clássico: menos elegante e graciosa, porem, mais clara e expressiva, mais determinada e concreta, mais simples e fixa.

As mais importantes inovaçōes na sintaxe de colocação: abandono quase total da ordem livre herdada do indo-europeu e a adoção da chamada ordem direta, tendência que se verifica em tôdas as línguas românicas, sem excluir o romeno. Nota, contudo, que em certos casos, a constante era a ordem inversa, nas linguas românicas, sobretudo na fase mais antiga, devido à influência erudita.

Na sintaxe de regência: o uso generalizado das preposiçōes, como característica principal, na introduçāo dos complementos, dos predicativos, dos complementos adnominais e dos complementos circunstanciais.

Na construção do período: o empobrecimento da subordinação processo normal na lingua clássica - e a preferência à parataxe. Dasubordinação ainda restaram as orações substantivas, as relativas e as condicionais. Outra caracteristica, digna de nota pela sua freqüência nas linguas românicas, sobretudo no período medieval, é a omissão da conjugação subordinativa; daí, a construção assindética das oraçōes subordinadas.

Na 4. a e última parte da obra, são apresentadas as muitas peculiaridades do léxico do latim vulgar, em contraste com o do latim clássico: têrmos próprios da língua do povo; formas de empréstimo de línguas itálicas (osco-umbro, etrusco, etc.) ou dialetais, do grego, do céltico, de línguas ibéricas e germânicas; particularidades semânticas das formas populares; o processo de formação de palavras, através da composição e da derivação.

Os textos do latim vulgar que lhe serviram de apoio para corroborar o seu ponto de vista: De lingua latina (Varrão), o Appendix Probi, Cena Trimalchionis, Peregrinatio ad Loca Sancta, Mulomedicina Chlronis, Isidori hispalensis episcopi etymologiarum sive originum libri $X X$ e o Tetraevangelio.

Além das melhores antologias do latim vulgar, o autor compulsou mais de uma centena de outras obras, o que lhe proporcionou extraordinária solidez de conceitos e de doutrina.

Constitui, portanto, a Gramática do Latim Vulgar do Prof. Theodoro Henrique Maurer Jr. um manual de consulta e estudo obrigatório por todos quantos se preocupam em melhor conhecerem o assunto nêle contido e assim, com mais segurança realizarem as pesquisas pertinentes à Lingüistica Românica. 
Ansiosamente aguardamos que o Prof. Theodoro Henrique Maurer Jr. traga a lume o trabalho que anuncia no prefácio desta obra. Será, não há dúvida, um utilissimo complemento sobretudo à Gramática do Latim Vulgar que, mui perfunctòriamente e sem pretensão de espécie alguma, tivemos a honra de comentar, apresentando-a aos leitores da revista Letras.

\section{Miguel Wouk}

\section{G. LIPPARINI - A. SANTIAGO DE OLIVEIRA - SINTAXE LATINA - Editôra Vozes, Petrópolis, R. J., 1961, pp. 480.}

Eis um livro didático e útil. Lipparini é um latinista conhecido desde muito, na Itália, e sua obra La Sintassi Latina, serviu a numerosas geraçōes de alunos nas escolas daquele país. Agora Alípio Santiago de Oliveira traduziu-a em português, atualizando-a e aumentando-a consideràvelmente.

A matéria é tratada, no volume, conforme esta ordem: A Concordância - Uso do Nominativo - Uso do Acusativo - Uso do Ablativo - Os Complementos de Lugar, Tempo e Espaço - Uso do Genitivo - Uso do Dativo - Uso especial dos Nomes e Pronomes - O Uso dos tempos - Os Modos nas Oraçōes Principais e Dependentes - Uso do Infinito - Uso do Particípio - Uso do Gerúndio e do Gerundivo - Uso do Supino - Os Modos e os Tempos nas Proposiçōes coordinadas - Os Modos e os Tempos nas Proposiçōes Subordinadas - A "Consecutio Temporum" - A "Oratio Obliqua" - APENDICE: Resumo geral da morfologia latina - Noçōes de prosódia e métrica O calendário romano - Vocabulário de têrmos mais usuais e modernos - Pequena guia de conversação.

A parte teórica é ilustrada por exercícios práticos sempre de grande útilidade. Despertam interêsse, pela novidade, os apêndices: Têrmos mais usuais e modernos - e Guia de conversação.

Trata-se de um bom livro, que prestará reais serviços aos estudiosos da língua latina. A Editôra Vozes apresentou ao público estudantil um livro agradável, claro, didático e em ótima veste tipográfica.

Luigr Castagnola

ANITA SALMONI CEVIDALII - GINEVRA GAMBIRASIO - LETTURE ITALIANE PER BRASILIANI - Ediçōes Loja do Livro Italiano, São Paulo, sd., pp. 488.

Non sono molti i libri d'Italiano pubblicati nel Brasile ad uso di quelli che vogliono o debbono studiare quella lingua. Meriti particolari ha conquistato, in questo campo d'attività, lo scrittore e professore G. D. Leoni, cattedratico di Lingua e Letteratura Italiana presso l'Università Cattolica di São Paulo e presso l'Università Mackenzie. 
Le due Autrici di questa antologia italiana per i Brasiliani hanno avuto una bella e utile idea. Bella, perché il libro è, sostanzialmente, ben organizzato; utile, perchè l'antologia in questione offre ottimo sussidio agli alunni dei corsi di Lingua Italiana esistenti nel Brasile.

L'antologia è divisa in tre parti. La prima raduna brani di facile lettura e comprensione, preceduti da una brevissima presentazione geografica, storica e linguistica d'Italia. A piè di pagina molte parole del testo sono tradotte in portoghese - valido aiuto per chi comincia a leggere testi in Italiano. La seconda parte contiene pagine di buoni scrittori italiani, moderni e contemporanei, generalmente noti nel mondo letterario d'Italia. La terza parte offre, secondo certo ordine cronologico, brani scelti di classici italiani, a partire da Dante fino ai giorni nostri.

Ci sembra, nel complesso, ben fata la scelta dei brani e degli autori; indovinati i rapidi cenni biografici relativi agli scrittori citati. A nostro avviso, tuttavia, sono troppo poche le pagine dedicate ad alcuni autori - Petrarca, Foscolo specialmente, ed anche Leopardi; e ci sembrano davvero troppe le pagine dedicate ad alcuni moderni, non a tutti. Inoltre, passare completamente sotto silenzio Machiavelli, Metastasio, Parini, Alfieri, Monti, De Sanctis, Zanella e Fogazzaro, non ci sembra giusto, volendo questa terza parte dell'antologia offrire un contatto sia pur rapido con la letteratura italiana. Ciò non toglie alle due Autrici il merito d'aver fatto una bella e utile pubblicazione, veramente atta a servire come ottimo libro di lettura a tutti quelli che desiderano, in Brasile, studiare la lingua e la litteratura italiana.

Sia permesso, tuttavia, fare qualche esservazione. Si ha l'impressione che non furono corrette le bozze delle note, poichè ivi sono molti gli errori tipografici. Esempi: passeira (p. 37), è con cic (p. 44), pinocchio (p. 57), Varco de Gama (p. 148), penetrô (p. 195), Romolo e Regno (p. 199), Michelagelo (p. 198), Numinotere (p. 199), Pedrocchi (p. 286). Ecc.

Non poche volte la divisione delle sillabe è fatta, erroneamente, così: Pas-coli (p. 6), pros-perità (p. 81), Cos-tantinopoli (p. 148), as-pirazione (p. 166), ris-posta (p. 198), sis-tematici (p. 199), significa (p. 216), tes-ta (p. 242). Ecc.

Comunemente si dice "Mar Nero" e non "mar negro" (p. 38).

La data di morte di Lorenzo il Magnifico è 1492, e non 1494 (p. 81).

A pagina 98, la note è incompleta: Per Pascoli vedi pag.

A pagina 151, Le Mie Prigioni del Pellico sono chiamate "romanzo autobiografico". Comunemente sono chiamate "memorie autobiografiche".

Il testo di certi brani, alle volte, è assai scorretto. Esempi:

$\mathbf{E}$ quanto a dir qual'era, è cosa dura invece di: 
Ah quanto a dir qual era, è cosa dura (p. 333).

invece di:

là dove termina quella valle

là dove terminava quella valle (p. 333) . invece di:

anzi impediva il mio cammino,

anzi impediva tanto il mio cammino (p. 334). invece di:

e dopo il pasto ha più fame che prima.

e dopo il pasto ha più fame che pria (p. 337).

Questi rilievi sono fatti unicamente nel senso di facilitare una futura edizione più corretta, e non hanno assolutamente l'intenzione di diminuire i pregi del volume, ben sapendo quanto sia difficile una perfetta edizione in lingua straniera.

\section{Luigi Castagnola}

\section{J. MATTOSO CAMMARA JR. - ALGUNS RADICAIS JE - Publicações avulsas do Museu Nacional, n.0 28, Rio, 1959, pp. 69.}

Esta obra é importante para o método da investigação lingüística em geral e particularmente para êsse grupo.

Na parte preliminar, introduçāo, é criticado o registro dos vocábulos que se têm coletado entre os silvicolas, visto que não se tem procedido "a uma análise mórfica rigorosa, que daria o semantema radical - ou núcleo significativo da palavra - ali integrado num conjunto de afixos variados". Deve-se, contudo, ressalvar a possibilidade de uma análise mórfica encarada segundo o interêsse do estudo. Assim, p. ex., pode-se proceder a uma simples comparação ingl. snow $=$ alem. schnee $=$ dinam. snee $=$ gót. snáizw $s=$ nórdico ant. snae-r, etc., porém frente ao lat. niui-s e ao grego niphá-s, temos uma anatomia desta natureza - ingl. s-now, alem. sch-nee, etc., ou então um lat. *sniui-s e um grego "sniphá-s.

O sueco $r i k=$ dinam. $r i g=$ isl. $r i k-r=$ gót. $r e i k-s=$ célt. $r i k-s$ $=$ lat. $r e g-s$, etc., mas ante o lat. $r e-s$, o sânscr. $r a-s$, temos o sueco $r i-k$, dinam. $r i-g$, etc.

Em seguida, M. Câmara apresenta doze línguas da família jê, as quais possuem listas dotadas de certas condiçōes para o cotejo acroá, apinajé, caiapó do norte, craó, crenié, meím (merrime), piocobié, rancocamecrā, suiá, taié, xavante e xerente. Segue-se o método de análise, depois a interpretação fonética, acompanhada de mui razoáveis considerações. 
Na parte referente às mudanças fonéticas e na parte especial, os fatos poderiam ser apresentados independentemente de especificação (elevação do timbre vocálico, labializaçāo, assimilação, etc.), uma vez que o estudo se dirige a especialistas, e ter-se-ia, então, favorecido a obra econômicamente, mas quod abundat,... Todavia, com essas especificaçōes prestar-se-á bom serviço aos principiantes.

Na parte especial, o A. compara 30 palavras, "têrmos nāo-culturais (que são os mais refratários ao empréstimo) e de caráter tão básico que se encontrem em qualquer língua".

A título de colaboração, tomo a liberdade para algumas observaçōes que me parecem necessárias:

Se, em "cabeça" kran (p. 15), o a se justifica, se em "cabelo" *khin (p. 16), o $i$ se justifica, se em "mão" *bkhra (p. 22), o $a$ se justifica, em virtude da ampla difusão dessas vogais em tais palavras nessas línguas, já o mesmo nāo sucede com *khra, "nariz" (p. 24), que melhor fôra postular *khre, dada a freqüência dessa vogal.

A favor do radical *kampru, "sangue" (p. 34) estão o craó kambro e o meim a-gaprú, i-gaprú, kaprô, segundo Th. Pompeu Sobrinho, Merrime - Indios Canelas - Etnografia, Gramática e Vocabulário, Fortaleza, Ce., 1930, p. 61. Ao lado destas formas há pudekrõ, "sangue" (p. 85), pudkrõ (p. 61) que talvez esteja por "pude-karó e êste por ${ }^{*}$ pude-kãro = kamro do caiapó (Ehr.) ?

Acrescente-se ao radical "kri, "frio" (p. 43) o meím $a-k r \ddot{u}-d$, $k r u ̈-d,-k r u$, "frio" (Th. Pompeu Sobr., o. c., p. 21, 27, 49, 68).

Melhor que o radical *kha:n, "pedra" (p. 45), com - $a$-, é hipotesar uma forma com $-e-$, pela abundância desta vogal (10 sôbre 5 , sem contar Xe. kina).

Para o vocábulo "sol", Th. Pompeu Sobr. (o. c., p. 62) registrou pütkúi que me parece possivel decompor e traduzir "fogo (kúi) do sol (püt)", conforme o exemplo de Xe. stakro, "calor do sol" (Nim.).

Esse autor (o. c., p. 62) anotou para "terra" as seguintes formas püuê, püê, pyê.

Câmara Jr. traduz o segundo elemento do radical "pyeka, "terra", 1. é, $k a$, como "branco" ("solo branco = areia"), que êle chama "elemento auxiliar", mas pode ser sinônimo do primeiro elemento, em vista do caingangue gá, ngá, "terra", pareci koá, id.

No item XXII, "cão" devia ser substituído por "jaguar" ou "onça". E aí se junte o meim róp (Th. Pompeu Sobr., o. c., p. 20); uróp-tuk, "onça preta" (id., ib., p. 56) ; urop-króro, "onça pintada" (id., ib., p. 56) ; rób-pó, "guará" (id., ib., p. 86); rob-lé, rop-lé, "gato" (id., ib., p. 86).

Em XXIII, "peixe", são mais numerosas as formas com - $e$ - do que as com $-a-$, logo deve supor-se o radical te:p e nāo ta:p. 
Parece razoável admitir-se uma protoforma "kwañoñ "cobra" (p. 54) para explicar wahi do Xa. e wai-i do Xe., mas são sacrificadas nada menos que 10 formas as quais postulam forçosamente o radical *kañon. Th. Pompeu Sobrinho, o. c., p. 43, averba kagó (p. 43 e 70), kaño (p. 43) e kaño (p. 27) para o meím.

Em XXV, "branco", supre-se a vaga do meím com o que foi coletado por Th. Pompeu Sobr. (o. c. p. 39) : antá, akáto, akád (êste na p. 67). Esquisita, assim me parece, a primeira forma. Estará por anká?

Th. P. Sobr. (o. c.) acolheu para "bom" e "bonito" as formas impeit, impéie, impeid (p. 39), peide (p. 25), impéide, como adv. (p. 29), pé (p. 33), péi (p. 33), impéd (p. 39). As formas com -e-, mais numerosas (v. XXVI), favorecem o radical mpe que não mpa.

Câmara Jr. "suspeita uma relaçāo obscura " entre o rad. II pse (Xe.) e o rad. I $m p a$, melhor mpe. Essa relação poderia ser explicada por uma forma que partisse de *pe-te e assim evolui _ ${ }^{*}$ petsé> "ptse> pse.

Quanto à forma wae do Xa., talvez se esclareça, se partirmos de uma forma aproximada de Ra. pai (hipa:ite), i. é, pai>*bai>*pai $>$ wae, ou mesmo de *mbei de Ra: "bai> wae.

O suiá haha, "bom", duplicação de "ha, é de natureza interjetiva, assim penso, e faz equação com o caingangue $h \hat{a}, h h a ́$, "bom".

No caiapó do pe. Antônio Maria Sala, O. P. (Ensaio de Gramática Kaiapó, "Rev. do Museu Paulista", t. XII, 1920) met é "bom" e "bonito".

Visto que a forma apinajé para "branco" foi traduzida, por hipótese, como "cabeça branca" (p. 54, nota 26), é bem provável que a forma acroá (XXVII, p. 57) s'ikutsakrañ (M.) seja igualmente uma locução e que se deva traduzir como "cabeça preta", e, em conseqüência, o radical II deve supor-se $k a \tilde{n}$ que, além disso, é mais razoável frente às formas de Kay. e Xe., e para o Kay. kañgro, então, passa a ter por ascendente "kañkro. E, por outro lado, é possível ligar -kro com opaié-xavante kōrá, kãorá, -kaorá-e, "prêto", com o pareci kieré, "prêto", com o araucano kuri, kuru, kurrü, "prêto".

Th. P. Sobr. registrou "prêto" em meím sob as formas tuk, tug (o. c., p. 88) .

Ainda que seja viável admitir-se o Ak. indz' ungama com dois radicais sinônimos para "pai" (p. 60), eu estou inclinado a traduzir o segundo elemento *ngama como "homem", e a favor do quê temos em várias línguas americanas êsse radical (v. os meus Estudos sôbre a Lingua Camacã, p. 316, "in" "Arquivos do Museu Paranaense", IV, 1945). E assim o radical II de "pai" ficaria mama, reduplicação, e freqüentíssimo universalmente. 
Th. Pompeu Sobr. (o. c., p. 56) recolheu intsun, itsiun, itiun, "pai", e para "comer" ampokre, amkre, gukre, gôkre.

A favor do radical *khren, "comer", posta-se o masacará krüng e o camacã kein-grin.

A modelar obra de $J$. Mattoso Câmara Jr. apresenta no fim a parte que julgo mais importante, uma vez que é conseqüência do estudo comparativo efetuado - as mudanças fonéticas ("as mudanças fonéticas preferenciais comprovam e completam a subdivisāo que a distribuição dos afixos nos fêz esboçar"), as variantes radicais ("de maneira geral, por sua vez, a distribuiçāo das variantes radicais confirma o quadro classificatório que acabamos de expor"), e, acima de tudo, a conclusāo - quadro classificatório das 12 línguas jês.

R. F. MANSUR GUÉRIOS.

ARTUR DE ALMEIDA TORRES E ZELIO DOS SANTOS JOTA - VOCABULARIO ORTOGRAFICO DE NOMES PROPRIOS - Editôra Fundo de Cultura, Rio, 1961, $411 \mathrm{pp}$.

Preenche a obra uma lacuna deixada pela comissāo organizadora da ortografia oficial de 1943, pois a tarefa da Academia Brasileira de Letras seria completa, se se publicasse o vocabulário onomástico que essa entidade prometera nesse mesmo ano.

Os filólogos patrícios Artur de Almeida Tôrres e Zélio dos Santos Jota alcançaram o resultado satisfatório que obteria a obra, se tivesse partido da Academia.

Abrange topônimos e antropônimos e nestes se incluem nomes mitológicos.

Nāo é um vocabulário etimológico ou elucidativo, de definiçōes, mas uma vez que outra a etimologia é chamada a prestar seu depoimento (Marlene, Erminia, etc.) ou depoimento justificativo da ortografia (Savedra, Sequeira, etc.). Alista apenas uma grande quantidade para mostrar ao leitor como os nomes próprios devem ser grafados (o título da obra já o diz). Eerdade que numerosos verbetes poderiam ser dispensados, em virtude de sua escrita nāo oferecer qualquer dúvida: Acre, Agadir, Alfenas, Baltar, Berto, Caldas, Clio, Domingos, Itamar, Pedro, Pinho, Pinheiro, Sara, Sodré, Taborda, Ubaldino, etc. Ter-se-ia economia de papel. Nada obstante, pode-se justificar a inclusão dêsses pelo préstimo da obra aos pais na escolha do nome para os batizandos.

Entre os topônimos, alguns trazem a localizaçāo geográfica Amparo (S. Paulo, Paraíba, Rio), Barracāo (Paraná, R. Gr. do Sul), Bela Vista (Pará, M. Grosso), etc. Não se sabe por que os demais não venham com essa indicaçāo, ou por que aquêles a trazem. Ademais, há Barracão também na Bahia e em Santa Catarina. 
Nem sempre o critério é o mesmo quanto ao topônimo estrangeiro - Aisne é postergado em favor de Axona (através do latim), mas Autum por Autun leva esta explicação: "Melhor aportuguesar que tentar o correspondente, através do latim Augustodunum". Se aportuguesaram numerosos estrangeirismos (Brunsvique, Champanha, Dijăo, etc.), por que não fizeram o mesmo com Bertagnolli? Se Oxforde foi preferido a Oxford, por que Beresfórdia e não Beresforde? $\mathrm{E}$ em Oxforde, aportuguesamento preferivel, deveriam os AA. lembrar-se da forma "clássica" Oxônia.

Em que pese à autoridade de Dauzat, no primeiro elemento de Ademar não se encontra atha, "pai", mas had-, "guerra" (germ. Hadumar, Hadamar, v. F. Solmsen, Indogermanische Eigennamen als Spiegel der Kulturgeschichte), e é o que consta no Vocabulário que ora examino, s. v. Hademar. Assim, etimològicamente, Hademar é o correto, como o é Ademar, se a fonte próxima fôr o francês Adhémar.

Os nomes Alháçane, Alhajame, Alhalim, Alháqueme, Alhuçaine, de procedência arábica, devem-se apresentar sem o $h$.

Se bem que seja comum Arduino, a origem reclama $h$ inicial. Cp. alemão Hartwin.

A tonicidade de $(H)$ aníbal, $(H)$ amilcar é a mesma de Assurbanipal e de Assurnasirábal, logo é assim que se há de recomendar.

Belchior e Melchior / belxior, melxior / sāo pronúncias defeituosas conseqüentes da escrita antiga $c h=k$. Embora hoje muito usuais, principalmente a primeira, seria de bom alvitre apor as formas recomendadas e etimológicas Belquior, Melquior (esta originária) e averbadas também.

Melhor que Belquisse é Belquis, de acôrdo com Belkis.

O inglês Bennett não pode e não deve ser substituído por Benato, porque é hipocorístico de Benedict e de Benjamin (W. Sunners, How to Coin Winning Names, N. Iorque, 1951) e M. Nurnberg e M. Rosenblum, Your Baby's Name, Clevelândia e N. Iorque, 1951).

Deve ser falha tipográfica Benoni, em vez de Benôni.

Brunot nāo corresponde exatissimamente a Bruno.

Pode ser que haja a pronúncia paroxitona Carmine, porém, errada, pois lembro o italiano Cármine, masc. e fem., o mesmo que Carmo, Cármen, Carmelo, Carmela.

Se Carol deve ser abandonado a favor de Carlos, por que registrar Carolino, - $-a$; empregue-se Carlino, $-a$ ! E Charles parece que não é arraigado entre nós!

Não sei por que Cavalcânti, com i, "destoa dos fatos da língua portuguêsa". 
Nomes em -on é que sāo esquisitos dentro do quadro fonético atual. Não obstante, os AA. nāo dizem nada ante Cilion, Címon, Alcon, Amon, mesmo tônicamente Ariston, Arnon, etc. Averbou Arion, mas Arion, oxitônico, é que é bem comum.

Melhor que Antar é Antar.

Se fazem questão de muito aportuguesamento, Clarissa é que seria recomendado e năo Clarisse.

Clémence deve ser mais bem substituido por Clemência que por Clementina.

Comte, dizem os AA., "como sobrenome deve guardar a feiçāo estrangeira". Muito bem! Estou de acôrdo, mas enfileirem-se Crespi (que nāo corresponde exatìssimamente a Crêspo), Cavalcânti, Accioli, Emmerich (que nada tem de ver com Américo, mas com o italiano Amerigo, paroxitônico), Fleury, Gastáldi, Goulard, Goulart, Hermann, Hernândez, Herrera, Humphrey, Moritz, Mosses, Paganini, Kepler, Seimens, Simson, Trujillo, Wagner, etc.

Se tomaram em consideraçāo $E d i$ "de $E d d y$, hipocorístico inglês de Eduardo", por que dar preferência a Nanci, em vez de Annecy?

O antropônimo Heli, do hebraico, "elevação, sumidade", nada tem de ver com o primeiro elemento de Elias, Eliézer, Eliseu, etc. Portanto, Eli é escrita falsa.

Estou de consêrto com o que se anota em Elza, mas sucede que Elsa é como escrevem (pronunciado elza) os numerosos membros da colônia germânica nos Estados meridionais. Quer dizer que Elsa é escrita puramente alemã.

A tradução dada ao nome Esméria no meu Dic. Etim. de Nomes e Sobrenomes não foi "nome de flauta", mas "nome de planta". Deve ter havido êrro tipográfico.

Em Hilo se declara - "nome da mitologia". Em outros exemplares nāo se diz nada.

No meu Dic. registrei Huáscar e assim também Nascentes.

Se se deve preferir Joana a Jane, por que, entāo, se recomenda Jeni (Jenny), quando, na verdade, esta forma corresponde mais ou menos a Joana? Por que Leni, se esta tem por base Helena? Por que Néli (e nāo Neli), se existe Nélia e a base Cornélia?

Não há por onde se pegue Leneu. O que é correto e que se deve recomendar, é Lineu.

Mançur, com ç, é errado, pois se trata não só de forma moderna, como também de forma introduzida aqui no Brasil. Não se encontra Mançur em documento luso antigo, mas, sim, Almançor, o seu corres- 
- pondente hereditário, introduzido em Portugal pelos mouros, elemento que obedeceu ao tratamento fonético vigente outrora na evoluçāo dos vocábulos arábicos. Embora sejam a mesma coisa, Mansur e Almançor (êste com o artigo) representam duas histórias distintas que não podem, nem devem ser confundidas. Procure-se em documentos arcaicos da Lusitânia e nêles encontra-se apenas a forma Almançor, que se poderia classificar de certo modo como popular.

Seguindo-se os AA., não teriamos Gerardo, Gilda, Gilberto, Adalgisa, etc., mas Guerardo, Guilda, Guilberto, Adalguisa, etc., de acôrdo com Guedes, Guerino, Guilherme, guisa, guildas, etc., mas a realidade é que esta série tem história diferente da anterior, por isto a diversidade.

Mansur é com -s-, como o são Násser e Nassim, segundo registram os mesmos Autores.

A forma verdadeiramente francesa é Michel e não Michael, que é erudita e rara (v. Dauzat, Dict. Etymologique des Noms...). E não me parece que Michael "já se integrou em nossa antroponimia".

A pronúncia Mônroe só se verifica entre pessoas cultas. No Rio, entre o povo, só se ouve Monrói.

Em Oscar convinha apor a nota de que em Portugal se pronuncia oscar.

Na parte antroponímica está deslocado o título Países Baixos.

Childerico é forma errada, embora se explique pelo italiano; a correta é Quilderico.

Se bem que Reinold seja cognato de Reginaldo, aquela forma ou, melhor, Reinoldo, aportuguesado, corresponde à forma germânica Reinhold, portanto se justifica.

Apesar de que no meu Dic. Etim. eu tenha afirmado que Sezefredo é forma aportuguesada de Siegfried, o que é errado, mas apenas correspondente, Sezefredo deve ter por ascendente uma forma teutônica com Se- (cp. Secco, Segga, Segestes, etc. "in" M. Schoenfeld, Woerterbuch der Altgermanischen Personen- und Voelkernamen).

Olfilas, Viola, proparoxitônicos, e não Ulfilas, Viola. 0 arábico Wadi deve ser preterido em favor de Uadi, mas não Vadi.

Tais são os principais passos da obra que me chamaram a atenção.

Faço votos que tenha alcançado seus objetivos!

R. F. MANSUR GUERTOS. 
J. MATTOSO CAMARA JR. - MANUAL DE EXPRESSÃO ORAL E ESCRITA - J. Ozon - Editor, Rio, 1961, 199 pp.

Se são felizes alunos por ter Mattoso Câmara Jr. como professor, essa felicidade, contudo, se estende a muitos, graças à publicação desta obra, a qual teve origem num curso sôbre Expressão Oral e Escrita, ministrado aos oficiais-alunos da Escola de Comando e Estado Maior da Aeronáutica. Posteriormente, foram essas aulas, ampliadas num pequeno Manual, utilizadas para o ensino de Português na Escola Normal, por iniciativa do prof. Hamilton Elia.

Graças a muitos colegas e amigos, de Câmara Jr., que insitiram na maior divulgaçāo da obra, deixou-se o A. vencer, "na esperança de ser com isso útil aos que necessitam de escrever ou falar em público por injunçōes da sua vida profissional".

Consta o Manual de 18 capitulos e subdivisões - a boa linguagem (a importancia da boa linguagem; língua oral e língua escrita); a elocução: funçāo expressiva (o tom e seu valor expressivo; a mímica) ; a elocuçāo: funçāo articulatória (a articulação em geral; a acentuação) ; a elocuçāo: função rítmica (o jôgo das pausas; as pausas e as partículas proclíticas); a exposiçāo oral (considerações gerais; o plano da exposiçāo; os prolegômenos da exposiçāo); a exposição escrita (caracterizaçāo; a redação); o plano de uma redação (consideraçōes gerais; as pesquisas e a bibliografia; a redação definitiva); a estrutura da frase (a constituição dos periodos; a análise lógica); a ortografia (considerações gerais; linhas gerais da nossa ortografia) ; correção da linguagem (o conceito de correção; as discordâncias do uso); a correção nas formas nominais (plural dos nomes; gênero dos nomes); a correção nas formas verbais; a correção nas formas pronominais (pronomes pessoais; tratamento; os demonstrativos); concordância e regência (concordância; invariabilidade; a regência); exame de algumas supostas incorreçōes (purismo e estrangeirismo; a rigidez gramatical); a escolha das palavras (consideraçōes gerais; os sinônimos; outros aspectos na escolha das palavras); a linguagem figurada (caracterizaçāo; uso da linguagem figurada); a clareza e seus vários aspectos; conclusão geral.

Com essa discriminação, terão os leitores, os interessados uma idéia do conteúdo.

Se me permite o A., tomo a liberdade para apor algumas observaçōes que me parecem não descabidas:

"E tal a sua importância [do tom] na linguagem, que, diz o A., na lingua escrita, onde êle nāo pode figurar, temos de recriá-lo na leitura mesmo mental, para podermos apreciar e até compreender o texto".

E verdade, mas também é freqüente o escritor lançar mão de explicação para salientar o tom de suas personagens, como nestes pas- 
sos de José de Alencar: "Amélia, tomando um tom imperativo, disse para o cocheiro: - Vamos! Vamos!" (p. 8). "Ao mesmo tempo acompanhava o movimento com estas palavras de contrariedade: - Como êle manda isto! Por mais que se lhe recomende!" (p. 9). "- Hei de possuí-lo!... exclamou êle com o tom com que Alexandre se prometeu o império da Ásia" (p. 18 - A Pata da Gazela, Coleção Saraiva, n. ${ }^{\circ}$ 125).

E pelo que respeita à mímica, igualmente o escritor é obrigado ao recurso da explicação: "...êle atirando-lhes um olhar de compaixão, dizia consigo:..." (idem, ibidem, p. 41). "Ao mesmo tempo fitava os olhos no môço para ver a expressão de sua fisionomia" (id., ib., p. 63). "O mancebo cravou em Amélia um olhar eloqüente, e disse com a palarra lenta e calma:..." (id., ib., p. 83). Nada obstante, fêz o A. breve alusão ao fato no cap. VI.

A pronúncia, p. ex., curitibana do $e$ como $e$, do o como $o$, contrária à pronúncia carioca (Manual, p. 35), é justificada pelo que o A. afirà p. 31: "Finalmente, há certos hábitos articulatórios que são próprios de uma determinada região do país e não coincidem como a norma geral de pronúncia", e não sofrem ridículo ante um auditório extra-regional, embora o A. ache "tão anômalo, que logo cria a impressão de sotaque estrangeiro".

O que, talvez, nāo seja pròpriamente ridiculo, entre nós, porém algo divertido, é o carioquismo de os lápis, os jarros, etc., que são pronunciados / oxlápix, ujjarrux /, etc. Mas é pronúncia regional... Ridicula, sim, é a pronúncia do caipira fora do seu meio.

A propósito das "linhas gerais da nossa ortografia", eu acho errado o ensinar que há só 24 letras em nosso alfabeto. Afinal, também consta isso em minha gramática! Se $k, y, w$ se usam, embora restritamente, não deviam ser excluidas do alfabeto. Elas têm nome como as demais letras, e o seu emprêgo é nāo menos importante que as outras e devem, pois, ser ensinadas, postando-as entre as outras.

Na parte da "seleção de letras equivalentes", nas palavras de origem não-latina, parece-me que não está claro o referente aos vocábulos de procedência arábica e tupínica.

A representação gráfica por $c$ (ante $e$, i), em vez de $s$, deve ter sido pela pronúncia peculiar do $c$ de outrora, que se aproximava de fonemas peculiares da lingua árabe. Igual fato se deu com o tupi. Os padres jesuitas registraram com $c$ também em atenção ao $c$ (ante $e$, $i$; $c$ ante outras vogais) do português quinhentista, porque assim ouviram aos indios costeiros, ou, em outras palavras, os tupis possuíam também êsse fonema /ts/, uma africada surda. $E$ a representação de $j$ (ante $e, i$ ) deve-se, com tôda a certeza, ao fato de êsse fonema, no português antigo, diferir na pronúncia do $g$ (ante $e, i$ ), que era $/ \mathrm{dj} /$.

Parece-me que tal se pode aplicar aos vocábulos de origem africana - jiló, vunje, etc. 
Não com ch, porque outrora era proferido $/ t x /$, mas com $x$, de puxar, etc., e que ficou reservado a vocábulos que possuíam tal som: em vocábulos do inglês - xerife (sł̌eriff), xale (shawl), etc.; contudo chutar; de línguas africanas - xangô, muxiba, etc.; do espanhol xicara (esp. arcaico xicara), etc.; do árabe - xeque, xerife (contudo chafariz), etc.

Mas, com $c h$, se corresponder à pronúncia /tx/ atual ou não: cheque (ingl. check), charlatão (ital. ciarlatano), chacota (esp. chacota), chantre (fr. chantre), etc.

Enfim, tais observaçōes não empanam, absolutamente, obra tão valiosa, com páginas redigidas com sobriedade e ricas de ensinamentos e reflexōes.

R. F. MANSUR GUtRIOS.

\section{NAIEF SAFADY - INTRODUCGAO A ANALISE DE TEXTO - Livraria Francisco Alves, S. P., Rio, B. Horizonte, 1961, 129 pp.}

Eis um livrinho que, de aspecto modesto, bem modesto, possui, no entanto, grande valia pela novidade em nosso meio intelectual a análise critica de textos literários.

O A., ex-aluno do prof. Antônio Soares Amora, é docente livre de Literatura Portuguêsa na Universidade de $\mathbf{S}$. Paulo, e catedrático da mesma disciplina em instituição estadual - a Faculdade de Filosofia de Assis.

Sua obra, que deve ser considerada cartilha, vademécum do acadêmico đe Letras, consta de uma "introduçāo geral", que se subdivide em "leitura" e "análise de texto". Em seguida - "o texto poético" abrange "preliminares" (começa aqui o A. a trabalhar fundamentalmente com o poema de Almeida Garrett - "Barca Bela"), "leitura ritmica", "leitura lógica", "compreensão integral", "ordenação do material", "ficha de leitura", "ficha de tópicos", "análise", "dialética", "temas de análise".

Na 3.a parte da obra - "o texto de prosa de ficção" - são abicados os seguintes itens: "preliminares", "técnica de composiçāo", "análise dos problemas de técnica de composição", "problemas de conteúdo - hipóteses de análise". Por fim, o "apêndice" - o poema "Barca Bela" e o trecho de prosa "O Filho" (O Pais das Uvas de Fialho de Almeida), o qual também mereceu análise literária, a título exemplificativo. E fecha o volumezinho com uma bibliografia (das obras citadas nêle).

Num dos seus capítulos, afirma Naief Sáfady: "A compreensão plena de uma obra depende exclusivamente do leitor. Não se ensina a compreender uma obra. Todavia, é possível orientar a descoberta dos elementos de um texto literário, em demanda dessa compreen- 
são plena. Essa é a modesta tarefa da análise de texto: propiciar ao leitor de uma obra alguns caminhos para a compreensão dela". E chama atenção para possível engano: "Análise de texto não é crítica literária. Análise de texto serve exclusivamente aos limites da compreensão do objeto lido, compreensão no mais alto sentido (e também no mais profundo). A crítica vai além da simples compreensão: é uma forma superior de criação, baseada numa filosofia de valores". $\mathbf{E}$ assim conclui êsses passos: "Nesses têrmos, a análise de texto deve anteceder, metodològicamente, aos estudos de história literária, que requerem abundante instrumentação de trabalho e investigação, e cujo cerne está, precisamente, na obra literária".

Faço votos que seja bem auspiciosa a difusão da presente obra, pois, no dizer do prefaciador Antônio Soares Amora, "já é tempo de superarmos, no Brasil, o ensino da Literatura confinado exclusivamente na historiografia literária". $\mathrm{E}$ acrescenta em seguida: "Livros como êste, com raras qualidades de saber atual e métodos de ensino, terão, estou convencido, papel decisivo na renovação dos cursos de Literatura em nossas faculdades de filosofia".

R. F. MANSUR GUÉrios.

\section{SILVIO ELIA - O PROBLEMA DA LINGUA BRASILEIRA - Instituto \\ Nacional do Livro, M. E. C., Rio, 1961, $180 \mathrm{pp}$.}

Por ocasião da 1.a edição desta obra (1940), tive ocasião de publicar breve apreciação na imprensa local, sustentando que a maior bateria contra a pretensa língua brasileira havia partido de Silvio Elia, em virtude de seus conhecimentos não só lingüisticos, mas ainda filosóficos, e êle assim terminava a introdução da 1." edição: "Na verdade, o que poderemos afirmar neste assunto resulta da compreensão que tenhamos da natureza do fato lingüístico, e essa compreensão não é científica, no sentido restrito em que os modernos empregam tal palavra, porque não se dirige para o simples fenômeno lingüistico, e sim para a sua natureza, para a sua essência, para o seu nôumeno. E, portanto, é filosófica".

A presente edição vem enriquecida de observações bibliográficas, notas complementares, acréscimos como no cap. intitulado "português e brasileiro", em que é citada a Introdução ao Estudo da Lingua Portuguêsa no Brasil de Serafim da Silva Neto, e citado M. Pidal, a propósito da opinião de Rufino José Cuervo sôbre a língua espanhola falada nas Américas, e a propósito de outras opinióes.

Entre os autores que trataram do português do Brasil, Silvio Elia, apresentando sucinto estudo, acrescenta êstes, não incluídos na $1^{\text {a }}$ edição: Virgílio de Lemos (p. 95 a 104), a propósito de A Língua Portuguêsa no Brasil, Bahia, 1916 - "notável sob vários aspectos". 
Prof. Gladstone Chaves de Melo (da p. 130 a 136) com A Lingua do Brasil, Rio, 1940; 2." ed. 1946 - "harmonioso trabalho".

Prof. Serafim da Silva Neto (da p. 136 a 141) com a Introdução ao Estudo da Lingua Portuguêsa no Brasil, Rio, 1950 - "síntese vigorosa e lúcida".

Outros trabalhos sôbre o mesmo assunto constituem o novo capitulo - "outras atitudes em face do problema".

Na parte final, conclui o A., e não poderia ser de outro modo, "pela unidade lingüistica entre Portugal e o Brasil". E em seguida: "Simultâneamente estabelecemos a diversidade estilistica, entre os dois paises. Nāo que haja um estilo nacional, com caracteres definidos, que tenha de romper os quadros da gramática portuguêsa. Isso seria o mesmo que afirmar a diversidade cultural e nós verificamos que, longe disso, o Brasil cada vez se integra mais na civilização do Ocidente". E adiante: "Como, porém, o brasileiro já vai apresentando uma nova mentalidade - americana, em contraposição à européia, e romântica em antagonismo com a clássica - essas variedades se infiltram em tôdas as nossas manifestaçōes de cultura, inclusive a lingua".

E, nesse tom, vai expondo outras facêtas.

E obra digna de leitura e meditaçāo!

R. F. MANSUR GUÉRIOS.

\section{ADRIANO DA GAMA KURY - LIÇOES DE ANALISE SINTATICA - Editôra Fundo de Cultura, Rio, 1961, $195 \mathrm{pp}$.}

Trata-se de um manual prático para o domínio da análise sintática. Seu autor, o prof. Adriano da Gama Kury, é um estudioso da novel geraçāo de filólogos que encaram os fatos lingüísticos sob o aspecto verdadeiramente cientifico.

Organizou ediçōes criticas da Oração aos Moços, de Rui, e do Bom Crioulo, de Adolfo Caminha. Foi revisor do Vocabulário Ortográfico da Lingua Portuguêsa, da Academia Brasileira de Letras (1943). Ł o responsável pela forma vernácula dos vols. IX a XVII da Comédia Humana, de Balzac, e dos vols. de Em Busca do Tempo Perdido, de Proust.

Seu nome tem sido muito divulgado, graças à publicação da $P e-$ quena Gramática para a Explicação da Nomenclatura Gramatical Brasileira, com numerosas ediçōes em breve tempo. também o autor de um vitorioso Português Básico.

A presente obra - Liçōes de Análise Sintática - teórica e práti- 
ca, escrita com muita clareza, como se requer, apresenta as suas partes divididas em pequenos capitulos, fáceis para a apreensão da parte do aluno.

Dentre os manuais de análise sintática que eu conheço, êste do prof. Kury é um dos melhores sob vários aspectos, e, certo, está fadado a grande difusão.

R. F. MANSUR GUÉRIOS.

ZELIO DOS SANTOS JOTA - DICIONARIO DE DIFICULDADES DA LINGUA PORTUGUESA - 2 vols. - Editôra Fundo de Cultura, 1960, $585 p p$.

Transmissão de ensino prático de Português, o A. arranjou o seguinte plano - no $1 .^{\circ}$ volume: parônimos, homônimos, formas variantes, ortografia, abreviaturas, ditongo e hiato, crase, nomes próprios, palavras aportuguesadas; e no 2.0: adjetivos afins, coletivos, superlativos, adjetivos pátrios, aumentativos, diminutivos, femininos, estrangeirismos, onomatopéias, plurais. Quase tôdas essas partes se acham em disposição de dicionário, o que facilita muito o manuseio.

Divisōes que merecem salientadas: formas variantes; adjetivos afins; adjetivos pátrios (em vista, principalmente da sua sistematização) ; os aumentativos e diminutivos apostos aos normais; feminino com mudança de significação.

Muito pequena é a lista dos femininos de personativos; poderia ser bem alongada.

Concordo, por fim, em vista do que se apresenta, concordo com os dizeres da propaganda, e faço-os meus: "Há muitas obras que resolvem dúvidas sôbre vários aspectos do nosso idioma, mas nenhuma resolve tão completamente alguns setores (compostos, adjetivos afins, parônimos e homônimos) e resolve tantas dúvidas globalmente como êste dicionário do estudioso prof. Zélio dos Santos Jota".

R. F. MANSUR GUÉrIos.

ARLINDO DE SOUSA - A PALAVRA “QUE" $-J$. Ozon - Editor,
Rio, $1961,148 p p$.

E incrivel a atividade do prof. Arlindo de Sousa! São numerosos seus trabalhos - assuntos históricos, etnográficos, lingüisticos. Agora acaba de publicar o presente volume, assim intitulado, e em que se declara - "Modos de conhecer a natureza léxica do "que" - natureza léxica - função sintática - o "que" português em relação com a morfologia, sintática, semântica e estilística latina". Como o A. é perfeito latinista, conclui-se que a obra tem segurança também por êsse lado. Destina-se aos estudantes do curso secundário, do ensino superior, e a professôres.

R. F. Mansur Gứrios. 


\section{JOÃO GUIMARĀES - LINGUAGEM CORRETA - Editôta Fundo de \\ Cultura, Rio, 1960, $272 \mathrm{pp}$.}

Obra de português prático, apresenta-se com êste plano: Como se formou a Lingua Portuguêsa. Existe "realidade" para uma Língua Brasileira? Concordância dos pronomes de tratamento: Você, Vossa Senhoria, Vossa Excelência... O recurso quando não há familiaridade nem cerimônia. Adjetivos pátrios referentes aos Estados e Territórios brasileiros e às respectivas capitais. Adjetivo, artigo, preposição, substantivo e verbo figuram em locuçōes nas quais o elemento principal é a palavra "mão". Em ordem alfabética, são indicadas as melhores formas de palavras e expressões de uso necessário.

Parece que nāo estão claras as três linhas referentes à identidade luso-espanhola (p. 13). Tratar-se-á de identidade luso-galega?

No barroquismo (p. 14) devia o A. ressalvar, entre outros, o pe. Vieira. E Mendes dos Remédios: "Nāo quer isto dizer que tudo fôsse absolutamente mau nessa escola, nada se salvando das produções literárias que ela abrange, pois muitas revelam originalidade, beleza, gôsto apurado e rico de côres"... (Hist. da Lit. Port., 6. ed., p. 312).

A influência do francês no vernáculo (p. 16) já se verifica antes do século XVIII.

Nāo sei por que o A. reservou um cantinho para os Enciclopedistas! Deveria, sim, aludir aos elementos divulgados pela Revolução Francesa! Ver o meu despretensioso Vocábulos Característicos da Revoluçāo Francesa "in" Revista Filológica, Rio, 1942, n. 21, p. 47 a 49.

Em que pese à autoridade de Marques da Cruz, planicie, montanha e mar servem perfeitamente de tema para divagaçōes românticas... Não tem o menor fundamento o que se afirmou. A fala cantada é conseqüência do marulho das vagas? Mas a realidade é que não há lingua que nāo seja cantada!

Há ainda outros senões - lana caprina - mas isto e aquilo não desmerecem o valor da obra, o sumo - português prático!

R. F. Mansur GuÉrios.

CLOVIS MONTEIRO - ESBOÇOS DE HISTORIA LITERARIA - Livraria Acadêmica, Rio, 1961, 292 pp.

As liçōes ministradas pelo recém-falecido prof. Clóvis Monteiro no Colégio Andrews, do Rio, foram taquigrafadas pela então aluna Mariana de Lorena Moreira Bastos, a quem, pois, se deve também a presente obra. Diz o A. que a "publicaçāo me pareceu necessária, por conterem correçōes a erros e equívocos de críticos brasileiros e portuguêses, sobretudo no que toca à posição de Gil Vicente na história do teatro ibérico, à interpretação de certos pontos da história do Classicismo, principalmente no periodo arcádico, e ao Romantismo, nas suas origens e evolução nas literaturas européias". 
Os "Esboços" têm como titulos principais: introdução à história da literatura brasileira; primeiras letras no Brasil; musas do Brasil Colonial; prosa culta no Brasil Colonial; academias literárias; arcadismo; transição do classicismo para o romantismo na literatura brasileira; o romantismo; realismo e naturalismo; um quinhentista no século XX (José de Abreu Albano).

Obra escrita com clareza, segurança, é essencialmente didática, e ilustrada com breves textos de alguns autores. Destina-se principalmente aos alunos do curso colegial, aos que se destinam às faculdades, e mesmo para os alunos dos cursos superiores de letras.

R. F. Mansur Gutrios.

P. JOSE F. STRINGARI - CANHENHO DE PORTUGUES (Fatos AvUlsos de Linguagem) - Editorial Dom Bosco, S. Paulo, 1961, 167 pp.

O A., pe. José F. Stringari, salesiano, é nome conhecidíssimo nas letras filológicas, autor de dois prestimosos volumes, intitulados Regimes de Verbos, o primeiro, editado em 1936, e o segundo, em 1937. E professor da Faculdade de Filosofia de Lorena, onde, em seminário de Filologia Românica, teve a idéia, em colaboração com o prof. pe. Antônio Lages, catedrático de Português, teve a idéia de estudar os vários falares do interior de $\mathbf{S}$. Paulo, com auxílio dos alunos dessas localidades. Fruto dêsse empreendimento são as Pesquisas Lingüisticas Regionais que publicou no "Jornal de Filologia", n. 7 , v. III, fasc. 1, 1955, da pág. 19 à 26. Recolheu particularidades interessantíssimas da vila Luís Alves, no município de Itajaí, Santa Catarina.

O presente livro - Canhenho de Português - nasceu de "questiúnculas de linguagem" ventiladas "nas aulas, nas tertúlias ou em conversa à sombra das françudas figueiras que enchiam o pátio do Ginásio São Joaquim de Lorena". Foram publicadas, há 25 ou 30 anos, em fôlhas volantes e sobretudo na revista "O Grêmio", órgão do Grêmio Literário Joaquim Nabuco dêsse Colégio.

"Tenho a impressão, diz o A. dêsse tempo, de que se estudava e havia desejo de aprender". Mas, continua, "uma coisa havia que nāo era boa em língua portuguêsa. Era a mania dos clássicos. Mania prejudicial. As falas e os escritos deviam sair lardeados de quinhentismo, de seiscentismos e quejandos..., do contrário não era boa a linguagem".

"Compreende-se, mais adiante continua o A., compreende-se que se devem ler os clássicos da língua não para sua imitação servil, mas para thes apanhar aquêle feitio de dizer as coisas com elegância, vigor e clareza, sem o ranço de linguagem passada".

As faculdades de Filosofia é que têm contribuído muito para a renovação e renovação salutar, que atingiu o próprio autor e mesmo êste que subscreve estas linhas!

Além de liçōes práticas e sobremaneira valiosas do Canhenho, o 
A. encerrou nêle curiosos estudos: Preferências vocabulares (" $\mathrm{t}$ fato provado, diz o A., que falando ou escrevendo deixamos transparecer a nossa preferência por certos vocábulos ou torneios de expressāo"). Faz estatística de certos modos de dizer de D. Aquino Correia, do poeta Guilherme de Almeida (palavras exóticas), de Paulo Setúbal, de Graciliano Ramos, e citou estatísticas de outros investigadores.

As Pesquisas Lingüisticas Regionais, acima citadas, foram transcritas nesta obra. Fêz muito bem, para maior divulgaçāo!

Encerra o volume - Vozes e Sons - lista já publicada no "Grêmio" de Lorena, em 1935, mas agora algo melhorada.

Como vêem os leitores, e muito por alto, é bem variada a obra que o pe. Stringari houve por bem republicar. Não foi tarefa perdida. Há os que sabem apreciá-la, avaliá-la...

R. F. Mansur GUÉrios.

A. SALMONI E A. MAINA - CORSO DI LINGUA ITALIANA - Vol. I, 2. a ed., pp. 256 - Livraria Nobel, São Paulo, 1960.

A. SALMONI CEVIDALLI - CORSO DI LINGUA ITALIANA - Vol. II, (Perfezionamento), pp. 156 - Livraria Nobel, São Paulo, 1960.

La "Livraria Nobel" ha già acquistato meriti indiscutibili per la diffusione del libro italiano e, in particolare, per la diffusione della Lingua Italiana nel Brasile. Ricordiamo la pubblicazione di una serie di lavori del Professor Giulio Davide Leoni, tra cui la "Gramatica Italiana para os Brasileiros", e la "Antologia Italiana"; da qualche anno sta pubblicando pure la "Ressegna Brasiliana di Studi Italiani", meritevole della maggior diffusione tra quelli che s'interessano di questi studi.

Nel 1960 la stessa Libreria presentò agli studiosi della Lingua Italana "Il Corso di Lingua Italiana", in due volumi, delle Professoresse A. Salmoni e A. Maina. Sono due libri assai utili, presentati in eccellente veste tipografica, che presteranno valido aiuto a tutti quelli che vogliono imparare la Lingua d'Italia, una delle più armoniose del mondo.

Il primo volume è destinato ai principianti; oltre la parte strettamente grammaticale e teorica contiene diversi esercizi, letture e saggi di conversazione; il secondo volume è destinato alle persone che già hanno qualche conoscenza dell'Italiano e vogliono perfezionare le loro cognizioni di Lingua Italiana. Questo secondo volume, oltre un riassunto della grammatica, contiene pure molti esempi, nozioni di sintassi assai sviluppate, e una serie di brani di autori brasiliani per versioni dal portoghese in italiano.

E degno di lode lo sforzo fatto dalle Autrici, entrambe laureate in Università d'Italia e insegnanti di Lingua Italiana nell'Instituto Cultural Italo-Brasileiro di São Paulo. 